\title{
ANTIBACTERIAL EFFECT OF Er,Cr:YSGG LASER UNDER VARIOUS IRRADIATION CONDITIONS IN ROOT CANALS CONTAMINATED WITH ENTEROCOCCUS FAECALIS (In vitro study)
}

\author{
Saad El-Din S. EL-Gendy ${ }^{\prime *} B D S$, Sybel M. Moussa ${ }^{2} P h D$, Ashraf M. Zaazou ${ }^{2} P h D$,
} Marwa A. Meheissen ${ }^{3} P h D$

\begin{abstract} network. activated irrigation in root canals contaminated with Enterococcus faecalis. I $(50.00 \%)(P=0.005)$. disinfection. The use of $\mathrm{NaOCl}$ together with $\mathrm{Er}, \mathrm{Cr}$ :YSGG laser activation yields superior disinfecting results.

1- Instructor of Endodontics, Conservative Dentistry Department, Faculty of Dentistry, Alexandria University.

2- Professor of Endodontics, Conservative Dentistry Department, Faculty of Dentistry, Alexandria University.

3- Lecturer of Medical Microbiology and Immunology, Faculty of Medicine, Alexandria University.
\end{abstract}

INTRODUCTION: The fundamental aim of endodontic therapy is to completely disinfect the root canal and its three-dimensional tubular

OBJECTIVES: This in-vitro study compared the antibacterial effect of intracanal irradiation with Er,Cr:YSGG laser in dry condition to laser

MATERIALS AND METHODS: Twenty-six extracted human single-canaled lower bicuspids were used. Teeth were instrumented and autoclaved, and then three specimens were randomly chosen to serve as negative control. The remaining specimens were inoculated with Enterococcus faecalis for two weeks and then additional three specimens were selected to serve as positive control. The remaining specimens were divided into two equal experimental groups according to the disinfection procedure, Group I: Dry Laser Irradiation, Group II: Laser Activated Irrigation. Bacterial sampling was collected by both paper points and dentin chips from the canal walls and analyzed for the presence of Enterococcus faecalis using culture method. The CFU\% reduction of each group was determined in relation to the positive control. RESULTS: For the paper points method of sampling, a statistically significant difference was found between group II (99.60\%) and group I $(82.50 \%)(P=0.012)$. While for the dentin chips method, a statistically significant difference was found between group II (100.00\%) and group

CONCLUSIONS: Er,Cr:YSGG dry laser irradiation is not an alternative but a possible supplement to existing protocols for root canal

KEYWORDS: Er,Cr:YSGG laser, Dry irradiation, Laser activated irrigation, Enterococcus faecalis, root canal disinfection

\section{INTRODUCTION}

The fundamental aim of endodontic therapy is to completely disinfect the root canal system and its three-dimensional tubular network (1). This aim is commonly achieved by mechanical instrumentation, irrigation with disinfecting solutions and inter-appointement intracanal medicaments.

Studies have shown some limitations of mechanical instrumentation due to deep bacterial penetration into accessory canals, isthmi and dentinal tubules $(2,3)$. Additionally, $35-53 \%$ of the root canal surface remains untouched during mechanical instrumentation (4). Sodium hypochlorite $(\mathrm{NaOCl})$ at concentrations ranging from 0.5 to $5.25 \%$ is still considered the 0 gold standard for root canal irrigation due to its wide antimicrobial spectrum of action and its ability to dissolve organic tissues (5). But, it has a limited depth of penetration inside the dentinal tubules and as it acts only by direct contact with the bacteria targeted, $\mathrm{NaOCl}$ has a limited antibacterial effect in deeper dentinal layers (6).

Despite improvements in instrumentation techniques and the use of intracanal medicaments, endodontic treatment can still fail. Researchers have attributed such failure to incomplete eradication of microorganisms from root canals and the presence of persistent infection (7). Enterococcus faecalis is the most prevalent microbial species found in root canals of failed endodontic therapy. It accounts for 64$78 \%$ of cases with persistent or secondary infection (8).

The eradication of persisting bacteria in the root canal system is considered a major challenge in today's treatment regimens and is crucial for the long-term success and preservation of the endodontically treated tooth (9).

Multiple treatment modalities and technologies have been introduced in the endodontic field aiming at achieving superior disinfection of the root canal system prior to obturation. Among these, dental lasers may provide greater accessibility to inaccessible parts of the tubular network, due to their better penetration into dentinal tissues (10). Additionaly, the effect of lasers on bacterial surfaces visualized by atomic force microscopy revealed drastic alterations which is marked as changes in bacterial cell surface morphology together with multiple cell lysis signs (11).

In 2002, the U.S. Food and Drug Administration (FDA) approved the Erbium, Chromium: Yttrium, Scandium, Gallium, Garnet (Er,Cr:YSGG) laser for use in conventional and endodontic therapy (12). The Er,Cr:YSGG laser has a $2780 \mathrm{~nm}$ wavelength delivered by flexible fiber optic tips. This laser wavelength has the highest absorption in water and high affinity to hydroxyapatite (13). 
The present study is intended to compare the antibacterial effect of Er,Cr:YSGG laser irradiation in dry root canals to laser activated irrigation inside root canals contaminated with Enterococcus faecalis. The null hypothesis is that there is no difference in terms of antibacterial effect between the two tested groups.

\section{MATERIALS AND METHODS}

\section{Specimen preparation and sterilization}

The study protocol was approved by the ethics committee of the Faculty of Dentistry, Alexandria University. Twentysix extracted human single-canaled lower bicuspids with fully developed root apices were selected for this study. The teeth were cleaned from any soft tissues or calculus deposits then stored in isotonic saline solution at $100 \%$ humidity and $37^{\circ} \mathrm{C}$. After caries removal, a conventional access cavity was prepared in each tooth using high speed round bur and Endo-Z bur (Dentsply-Maillefer, Ballaigues, Switzerland) under water cooling. The specimen length was set to be $16 \mathrm{~mm}$ and the extra part was resected using diamond stone disc from the coronal end. The canals were checked by size $10 \mathrm{k}$-file to confirm apical patency. The working length was set to be $15 \mathrm{~mm}$. Root canals were prepared using One Shape files (Micromega, Besancon, France), $\# 25,6 \%$ followed by $\# 30,6 \%$, in a continuous rotation reaching an apical preparation corresponding to ISO size 30 and canal taper of $6 \% .2 \mathrm{ml}$ of $2.5 \% \mathrm{NaOCl}$ was used in between instruments. The smear layer was then removed using $1 \mathrm{ml}$ of $17 \%$ EDTA solution (Meta-biomed, Chungbuk, Republic of Korea) for 1 minute followed by 4 minutes' final rinse with $2.5 \%$ $\mathrm{NaOCl}$. Then copious irrigation with sterile saline was done. The apical foramina of different specimens were sealed with type II glass ionomer cement, Micron Superior (Prevest Dentpro, India). The outer surfaces of the roots were covered with two layers of nail varnish to limit the infection route only through the canal lumen. To facilitate handling and sampling, each tooth was mounted vertically in a plastic cryovial in heavy condensation silicone (Zetaplus, Zhermack, Rovigo, Italy). The whole assembly was then sterilized in autoclave at $121^{\circ} \mathrm{C}$ for 30 minutes. Three specimens were then randomly selected to serve as negative control.

The methods of bacterial suspension preparation, inoculation and bacteriological sampling employed in this study followed the protocol carried out by Mehrvarzfar et al (14).

\section{Bacterial suspension preparation and inoculation}

A pure bacterial culture of Enterococcus faecalis (ATCC 29212) obtained from Microbiology Diagnostic Laboratory, Faculty of Medicine, Alexandria University was inoculated in BHI broth and incubated for 24 hrs at $37^{\circ} \mathrm{C}$ under aerobic conditions.

E. faecalis culture in BHI broth was then calibrated to a concentration of $3 \times 10^{8} \mathrm{CFU} / \mathrm{ml}$ adjusted spectrophotometrically to match the turbidity of a McFarland 1 scale. Each root canal was completely filled with the E. feacalis suspension using sterile 1-ml insulin syringes and then incubated for two weeks under aerobic conditions at $37^{\circ} \mathrm{C}$. The inoculum inside the canal was replaced every other day. Every seven days, random sampling was done for gram staining to confirm the purity and viability of the E. faecalis cultures. After the incubation period, three specimens were randomly chosen to serve as positive control.

\section{Treatment of the experimental groups}

The BHI broth inside the canals was dried using sterile paper points. The specimens were randomly allocated into the two experimental groups of ten specimens each.

\section{Group I: (Dry Laser Irradiation)}

Root canals were irradiated with Er,Cr:YSGG laser (Waterlase, Biolase technology, San Clemente, CA, USA) using the $\mathrm{RFT}_{2}$. The tip was placed into the handpiece of the Waterlase ${ }^{\circledR} \mathrm{MD}^{\mathrm{TM}}$ device and inserted to the working length. Then the laser was activated and slowly withdrawn over a 10 -second interval. It was used three times against each wall (mesial, distal, buccal and lingual) for a total of 12 insertions made per canal ( 2 minutes per canal). The following settings were used as recommended by the manufacturer : $0.75 \mathrm{~W}, 20 \mathrm{~Hz}, \mathrm{H}$ mode, $10 \%$ air and no water (15).

\section{Group II: (Laser Activated Irrigation)}

Root canals were irrigated with $1.25 \mathrm{ml}$ of $2.5 \% \mathrm{NaOCl}$ solution. Then, it was activated by the Er,Cr:YSGG laser using RFT2 with its tip placed stationary $5 \mathrm{~mm}$ short of the working length, for 5 seconds. Such procedure was repeated 4 times with a total of $5 \mathrm{ml} \mathrm{NaOCl}$ and 20 seconds of laser activation. The following settings were used as recommended by the manufacturer: $1.5 \mathrm{~W}, 20 \mathrm{~Hz}, \mathrm{H}$ mode, $10 \%$ air and no water (16).

The canals were flushed immediately with $3 \mathrm{ml}$ of sterile saline following the disinfecting procedures, to remove any remnants of $\mathrm{NaOCl}$.

Bacteriological sampling from inside the root canals Immediately following the treatment done for each of the experimental groups, two sampling methods were employed:

\section{Sampling using paper points:}

The root canals were filled with $1 \mathrm{ml}$ of sterile saline solution and three sterile paper points of $\# 30$ were used, for each specimen. Each paper point was left inside the canal for 1 minute. Then, they were transferred to the corresponding sterile Eppendorf tube (Eppendorf-Elkay, Shrewsbury, MA, USA) containing $1 \mathrm{ml}$ of sterile saline.

\section{Sampling using dentin chips:}

A sterile $\mathrm{H}$-file $¥ 30$ was used to file vigorously the dentinal walls for 20 seconds. The resultant dentin chips were suspended using sterile saline. Afterwards, the canal contents were aspirated with a 1-ml disposable sterile insulin syringe and then placed into sterile Eppendorf tube containing $1 \mathrm{ml}$ of sterile saline $(14,17)$.

\section{Bacterial quantitative culture:}

Samples obtained by the two sampling methods, each separately, within the Eppendorf tubes were vortexed for 20 seconds. Serial 10-fold dilutions were done to a concentration of $10^{-7}$. Subsequently, $10 \mu \mathrm{l}$ of each dilution was applied to blood agar culture plates and incubated at $37^{\circ} \mathrm{C}$ for 48 hours. All procedures were carried under sterile and aseptic conditions. After the incubation period, the $\mathrm{CFU} / \mathrm{ml}$ was counted for each plate.

\section{STATISTICAL ANALYSIS OF THE DATA}

Degree of disinfection (CFU \% reduction) in the experimental groups was calculated in relation to the positive controls, following the method used by Gordon et al (18) and Mehrvarzfar et al (14). Data were analyzed using 
the Statistical Package for Social Sciences (SPSS ver.20 Chicago, IL, USA). The distributions of quantitative variables were tested for normality using KolmogorovSmirnov test, which revealed that the data were not normally distributed, so they were described using median, range. Comparing quantitative variables between experimental groups was conducted using Mann-Whitney $\mathrm{U}$ test. Level of significance of 0.05 was used, below which the results were considered to be statistically significant.

\section{RESULTS}

Negative and positive controls showed satisfactory results. Absence of bacterial growth was seen in the negative control blood agar plates, while the positive control plates showed extensive bacterial growth of about $2 \times 10^{6} \mathrm{CFU} / \mathrm{ml}$ by the paper points method of sampling and $2 \times 10^{4} \mathrm{CFU} / \mathrm{ml}$ by the dentin chips method. The median and the range (minmax) of the CFU \% reduction of the two experimental groups of both paper points and dentin chips sampling methods are shown in table (1) and figures $(1,2)$.

Table (1): Showing the median and the range of the CFU \% reduction of the two experimental groups by both paper points and dentin chips sampling methods

\begin{tabular}{|l|l|l|l|}
\hline \multicolumn{1}{|c|}{$\begin{array}{l}\text { Experimental } \\
\text { groups }\end{array}$} & $\begin{array}{l}\text { GroupI } \\
\text { (Dry Laser } \\
\text { Irradiation) }\end{array}$ & $\begin{array}{l}\text { Group II } \\
\text { (Laser } \\
\text { Activated } \\
\text { Irrigation) }\end{array}$ & $\begin{array}{l}\boldsymbol{P} \\
\text { value }\end{array}$ \\
\hline $\begin{array}{l}\text { CFU \% reduction by } \\
\text { paper points } \\
\text { sampling method } \\
\text { Median } \\
\text { Range (Min-Max) }\end{array}$ & $\begin{array}{l}82.50 \\
(50.0-100.0)\end{array}$ & $\begin{array}{l}99.60 \\
(90.0-100.0)\end{array}$ & $0.012^{*}$ \\
\hline $\begin{array}{l}\text { CFU \% reduction by } \\
\text { dentin chips } \\
\text { sampling method } \\
\text { Median } \\
\text { Range (Min-Max) }\end{array}$ & $\begin{array}{l}50.00 \\
(0.00-99.0)\end{array}$ & $\begin{array}{l}100.00 \\
(50.0-100.0)\end{array}$ & $0.005^{*}$ \\
\hline
\end{tabular}

*Statistically significant by Mann-Whitney U test.

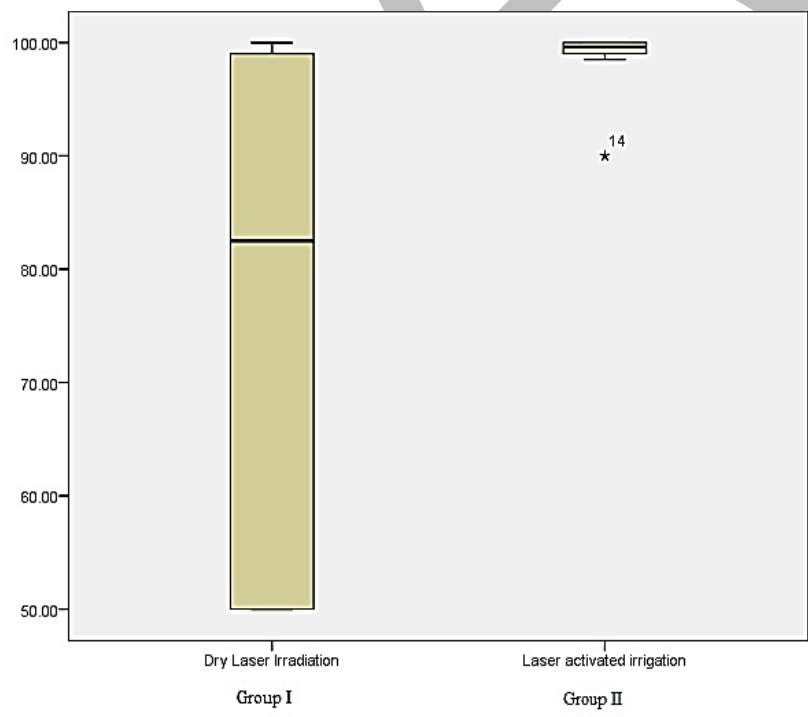

Figure (1): Box-plot showing the median and the range of the CFU\% reduction achieved in the experimental groups by paper points method of bacterial sampling.
For the paper points method of sampling, a statistically significant difference was found between group II (99.60\%) and group I $(82.50 \%)(P=0.012)$. Additionally, regarding the CFU\% reduction for the dentin chips method, a statistically significant difference was found between group II $(100.00 \%)$ and group I $(50.00 \%)(P=0.005)$.

Blood agar plates of specimens of both experimental groups sampled by both paper points and dentin chips method are shown in figures $(3,4)$.

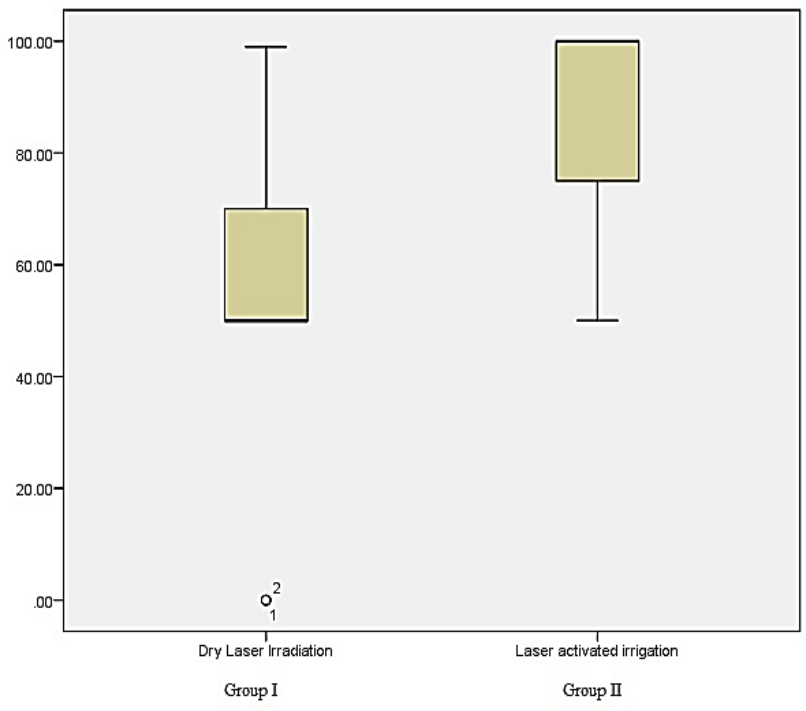

Figure (2): Box-plot showing the median and the range of the CFU\% reduction achieved in the experimental groups by dentin chips method of bacterial sampling.

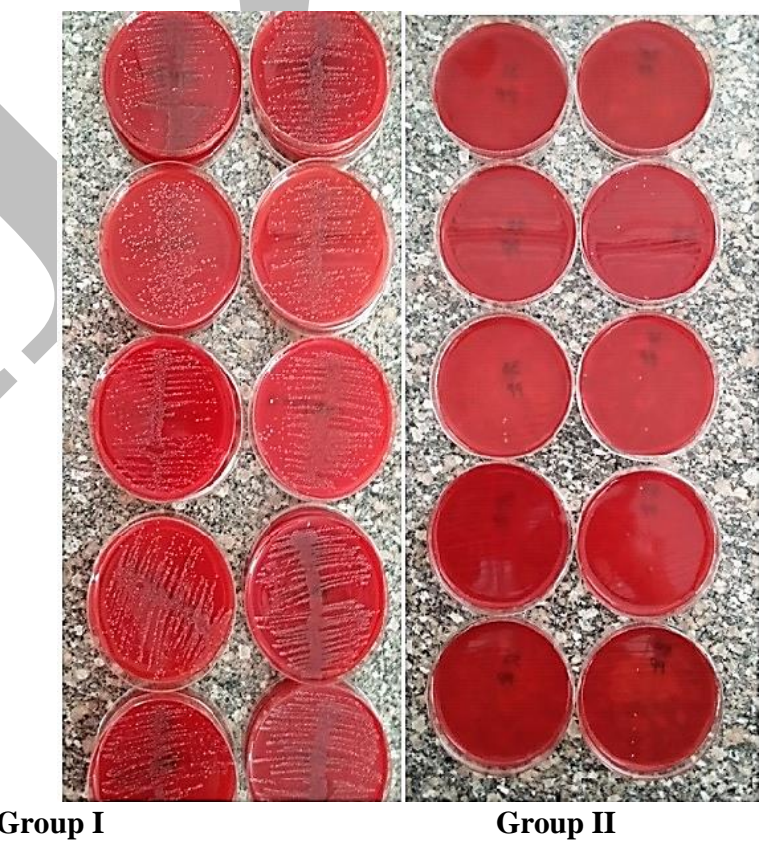

(Dry Laser Irradiation)

(Laser Activated Irrigation)

Figure(3): Showing blood agar plates of specimens of the experimental groups sampled by the paper points method.

\section{DISCUSSION}

In this study, root canals were inoculated with E. faecalis and incubated for a period of two weeks, in accordance with Mehrvarzfar et al (14) and Balic M. et al (17), as they revealed by SEM, heavy colonization of E. faecalis and a biofim-like structure on the canal surface after 15 days of inoculation (17). It was found that bacteria in biofilm are 
1000 times more resistant to antibacterial agents than plankotic bacteria and are more difficult to eliminate (19).

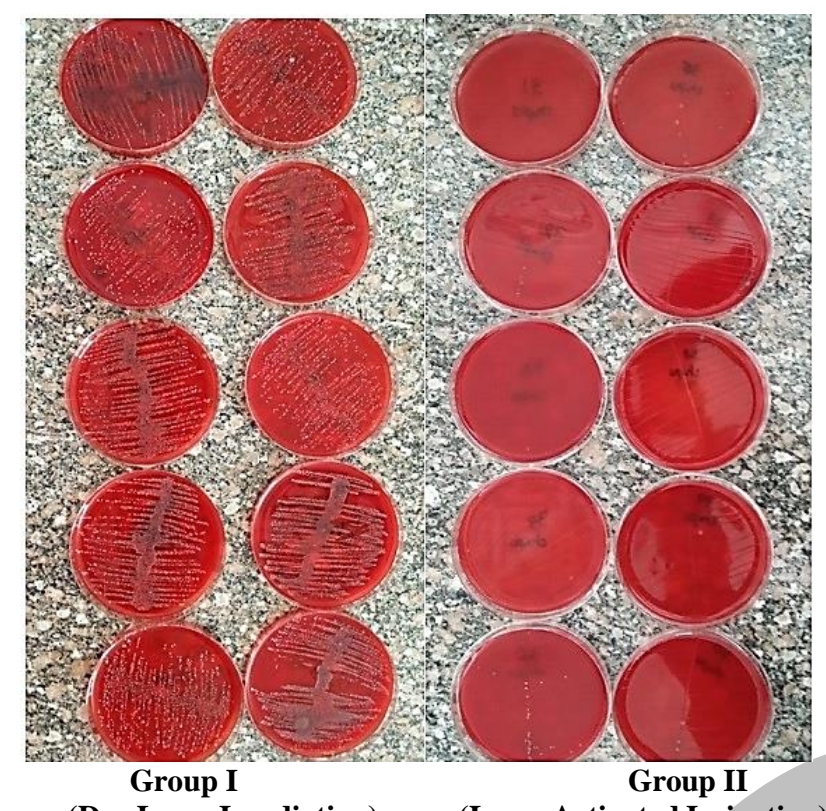

(Dry Laser Irradiation) (Laser Activated Irrigation)

Figure (4): Showing blood agar plates of specimens of the experimental groups sampled by dentin chips method.

The use of paper points is considered the conventional method of intracanal sampling. However it has some limitations, as the inability to sample bacteria in areas other than the main canal lumen such as accessory canals or isthmuses and also, bacteria that had invaded into the dentinal tubules would not be sampled (20). So, in this study, an additional sampling technique, collection of dentin chips, was used to overcome some of the aforementioned limitations. This method gives an idea about in-depth bacteria, as Peters et al (21) demonstrated that grinding and culturing of dentin gave better quantitative information about the extent of the infection.

The results of the negative and positive control blood agar plates confirmed both the methodology of sterilizing the specimens prior to bacterial inoculation and the process of bacterial colonization inside the prepared root canals.

In the current study, the dry laser irradiation group led to bacterial reduction of about $82.5 \%$ at $0.75 \mathrm{~W}$ which is comparable to the $77 \%$ bacterial reduction in the study carried out by Wang et al (9) at $1 \mathrm{~W}$, when sampled by paper points. This slight difference in the bacterial reduction may be attributed to the difference in the duration of laser irradiation which was 2 minutes in our study, while it was only 40 seconds in their study ,as Gordon et al (18) reported a decrease in the bacterial load when laser irradiation power and duration increased.

On the contrary, Yavari et al (22) found a higher CFU\% reduction for the dry laser irradiation group, $97.6 \%$ at $2 \mathrm{~W}$ and $98.47 \%$ at $3 \mathrm{~W}$ when sampled by dentin chips method. This difference could be attributed to the short incubation period employed in their study, only 48 hours, which is not enough for bacterial biofilm to form within the root canals (23). Also, higher power settings were used.

However, it was difficult to directly compare the results of the current study with that of the previous studies due to different methodologies, different incubation periods, different laser irradiation protocols and different sampling methods.

The high water content inside the targeted bacteria favors the absorption of Er,Cr:YSGG laser causing its destruction (24).

This accounts for the antibacterial effect of the dry laser irradiation group.

Owing to the strong absorption of the Er,Cr:YSGG laser energy into water and water based solutions such as $\mathrm{NaOCl}$, this laser is used to activate irrigating solutions inside root canals. Laser activation promotes the antibacterial action of $\mathrm{NaOCl}$ through cavitational effect. Cavitation is based on the creation of vapor bubbles inside the irrigant. The formed vapor bubble expands until irradiation pulse ends, then it starts to shrink until it implodes. At the moment of implosion, pressure waves traveling at supersonic speed (shock waves) and at sonic speed (acoustic waves) are generated within the irrigant. After total collapse of the vapor bubble, new smaller cavitation bubbles called secondary cavitation bubbles are formed due to the abrupt and extensive changes within the irrigant. Such high intracanal pressure waves create shear stress along the wall of the canal contributing to the disruption of bacterial cells (25-27).

The superior disinfecting effect caused by the laser activated irrigation over the dry laser irradiation reflects the importance of using an irrigant with an antibacterial action such as $\mathrm{NaOCl}$ in root canal disinfection. Also, the dry laser irradiation is insufficient to adequately reduce the bacterial load alone. This is may be due to the low power settings used in this study. This is in agreement with Seet et al (28) who reported that unless used with $\mathrm{NaOCl}, \mathrm{Er}, \mathrm{Cr}$ :YSGG laser alone did not eliminate the bacteria that had invaded the dentinal tubules. On the contrary, Gordon et al (18) reported that $\mathrm{Er}, \mathrm{Cr}$ :YSGG laser irradiation in dry conditions provided a more effective means of decreasing the CFUs than when used in wet conditions. But, in their study, wet conditions were done using the water spray, not the $\mathrm{NaOCl}$ irrigation. This can be explained by the fact that when water spray is used, part of the laser energy is absorbed by the water molecules in the water spray, decreasing the amount of laser energy reaching the targeted bacteria (18).

\section{CONCLUSIONS}

Within the limitations of the current study, it can be concluded that Er,Cr:YSGG dry laser irradiation, for the settings used, is not an alternative but a possible supplement to existing protocols for root canal disinfection. It can be also concluded that the use of $\mathrm{NaOCl}$ together with Er,Cr:YSGG laser activation yields superior disinfecting results.

\section{CONFLICT OF INTEREST}

The authors deny any conflicts of interest related to this study.

\section{REFERENCES}

1. Nair PR, Sjögren U, Krey G, Kahnberg K-E, Sundqvist G. Intraradicular bacteria and fungi in root-filled, asymptomatic human teeth with therapy-resistant periapical lesions: a long-term light and electron microscopic followup study. J Endod. 1990;16:580-8. 
2. Stuart $\mathrm{CH}$, Schwartz SA, Beeson TJ, Owatz CB. Enterococcus faecalis: its role in root canal treatment failure and current concepts in retreatment. J Endod. 2006;32:938.

3. Al-Nazhan S, Al-Sulaiman A, Al-Rasheed F, Alnajjar F, Al-Abdulwahab B, Al-Badah A. Microorganism penetration in dentinal tubules of instrumented and retreated root canal walls. In vitro SEM study. Restor Dent Endod. 2014;39:258-64.

4. Peters OA, Schonenberger K, Laib A. Effects of four Ni-Ti preparation techniques on root canal geometry assessed by micro computed tomography. Int Endod J. 2001;34:221-30.

5. Moorer WR, Wesselink PR. Factors promoting the tissue dissolving capability of sodium hypochlorite. Int Endod J. 1982;15:187-96.

6. Berutti E, Marini R, Angeretti A. Penetration ability of different irrigants into dentinal tubules. $\mathrm{J}$ Endod. 1997;23:725-7

7. Sjögren U, Figdor D, Persson S, Sundqvist G. Influence of infection at the time of root filling on the outcome of endodontic treatment of teeth with apical periodontitis. Int Endod J. 1997;30:297-306.

8. Chiniforush N, Pourhajibagher M, Shahabi S, Bahador A. Clinical Approach of High Technology Techniques for Control and Elimination of Endodontic Microbiota. Lasers Med Sci. 2015;6:139-50.

9. Wang Q-q, Zhang C-f, Yin X-z. Evaluation of the bactericidal effect of Er, Cr: YSGG, and Nd: YAG lasers in experimentally infected root canals. J Endod. 2007;33:8302.

10. de Souza EB, Cai S, Simionato MRL, Lage-Marques JL. High-power diode laser in the disinfection in depth of the root canal dentin. Oral Surg Oral Med Oral Pathol Oral Radiol Endod. 2008;106:e68-e72.

11. López-Jiménez L, Arnabat-Domínguez J, Viñas M, Vinuesa T. Atomic force microscopy visualization of injuries in Enterococcus faecalis surface caused by Er, Cr: YSGG and diode lasers. Med Oral Patol Oral Cir Bucal. 2015;20:e45e51.

12. Sulewski JG. Making the Most of the 16th Annual Conference and Exhibition: a practical orientation for attendees. Academy of Laser Dentistry 16th Annual Conference and Exhibition, 22-26 April 2009, Las Vegas, Nevada.

13. Coluzzi DJ. Fundamentals of dental lasers: science and instruments. Dent Clin North Am. 2004;48:751-70.

14. Mehrvarzfar P, Saghiri MA, Asatourian A, Fekrazad R, Karamifar K, Eslami G, et al. Additive effect of a diode laser on the antibacterial activity of $2.5 \% \mathrm{NaOCl}, 2 \% \mathrm{CHX}$ and MTAD against Enterococcus faecalis contaminating root canals: an in vitro study. J Oral Sci. 2011;53:355-60.

15. Dewsnup N, Pileggi R, Haddix J, Nair U, Walker C, Varella $\mathrm{CH}$. Comparison of bacterial reduction in straight and curved canals using erbium, chromium: yttrium-scandiumgallium-garnet laser treatment versus a traditional irrigation technique with sodium hypochlorite. J Endod. 2010;36:7258.

16. Bago Jurič I, Plečko V, Anić I. Antimicrobial Efficacy of Er, Cr: YSGG Laser-Activated Irrigation Compared with Passive Ultrasonic Irrigation and RinsEndo® Against Intracanal Enterococcus faecalis. Photomed Laser Surg. 2014;32:600-5.
17. Balić M, Lucić R, Mehadžić K, Bago I, Anić I, Jakovljević $\mathrm{S}$, et al. The efficacy of photon-initiated photoacoustic streaming and sonic-activated irrigation combined with QMiX solution or sodium hypochlorite against intracanal E. faecalis biofilm. Laser Med Sci. 2016;31:335-42.

18. Gordon W, Atabakhsh VA, Meza F, Doms A, Nissan R, Rizoiu I, et al. The antimicrobial efficacy of the erbium, chromium: yttrium-scandium-gallium-garnet laser with radial emitting tips on root canal dentin walls infected with Enterococcus faecalis. J Am Dent Assoc. 2007;138:9921002.

19. Costerton JW, Stewart PS, Greenberg E. Bacterial biofilms: a common cause of persistent infections. Science. 1999;284:1318-22.

20. Vertucci FJ. Root canal morphology and its relationship to endodontic procedures. Endodontic topics. 2005;10:3-29.

21. Peters LB, Wesselink PR, Buijs JF, van Winkelhoff AJ. Viable bacteria in root dentinal tubules of teeth with apical periodontitis. J Endod. 2001;27:76-81.

22. Yavari HR, Rahimi S, Shahi S, Lotfi M, Barhaghi MH, Fatemi A, et al. Effect of Er, Cr: YSGG laser irradiation on Enterococcus faecalis in infected root canals. Photomed Laser Surg. 2010;28:S91-6.

23. Kishen A, George S, Kumar R. Enterococcus faecalismediated biomineralized biofilm formation on root canal dentine in vitro. J Biomed Mater Res A. 2006;77:406-15.

24. Gutknecht N, Al-Karadaghi TS, Al-Maliky MA, Conrads G, Franzen R. The Bactericidal Effect of 2780 and $940 \mathrm{~nm}$ Laser Irradiation on Enterococcus faecalis in Bovine Root Dentin Slices of Different Thicknesses. Photomed Laser Surg. 2016;34:11-6.

25. Blanken J, De Moor RJG, Meire M, Verdaasdonk R. Laser induced explosive vapor and cavitation resulting in effective irrigation of the root canal. Part 1: a visualization study. Laser Surg Med. 2009;41:514-9.

26. De Groot S, Verhaagen B, Versluis M, Wu MK, Wesselink $P$, Van Der Sluis L. Laser-activated irrigation within root canals: cleaning efficacy and flow visualization. Int Endod J. 2009;42:1077-83.

27. Blanken JW, Verdaasdonk RM. Cavitation as a working mechanism of the Er, Cr: YSGG laser in endodontics: a visualization study. J Oral Laser Appl. 2007;7:97-106.

28. Seet AN, Zilm PS, Gully NJ, Cathro PR. Qualitative comparison of sonic or laser energisation of $4 \%$ sodium hypochlorite on an Enterococcus faecalis biofilm grown in vitro. Aust Endod J. 2012;38:100-6. 